\title{
Did misogyny win the 2016 american election?
}

\author{
Kate Manne:
}

\section{Down Girl: The Logic of Misogyny}

Oxford University Press, 2018. 368 pages. Price: 289,95 DKK

\author{
By Sidsel Jelved Kennild \\ Master of History of Ideas, Ph.D. student with the Department of \\ Philosophy and History of Ideas, Institute for Culture and Society, \\ Aarhus University
}

Down Girl has been called a new feminist classic. This can be ascribed to Kate Mannes's objective to unearth the seemingly persistent misogynistic patterns in allegedly post-patriarchal parts of the world, specifically focusing on the US and Australia. It is however also an attribute of the moment of publication in which feminists and liberals were wondering why an experienced woman like Hillary Clinton lost the election in favour of notorious pussy-grabber Donald Trump. Manne's answer: Misogyny caused Clinton to lose $(255,278)$.

Coming from the tradition of analytical philosophy, Manne's vantage point lies at the conceptual level. From this basis, she conceptually scrutinize misogyny and advances to the ameliorative project of conceptual ethics and engineering (33) as well as to critical engagement with current events, cultural productions, media, legal cases and the Isla Vista Killings. Thus, she argues against "the naïve conception" in which misogyny primarily is "a property of individual agents (typically, although not necessarily men) who are prone to feel hatred, hostility, or other similar emotions toward each and every woman, or at least women generally, simply because they are women" (33). According to Manne, the naïve conception renders misogyny marginal in any context, because most people have mothers, sisters and/or women friends whom they love, and therefore they cannot harbour true misogyny. Instead Manne proposes an ameliorative account of misogyny as "primarily a property of social systems or environments as a whole, in which women will tend to face hostility of various kinds because they are women in a man's world (i.e. patriarchy), who are held to be failing to live up to patriarchal standards" (33). Manne then understands misogyny in terms of what it does (20), and she shifts the focus from the internal, psychological attitude of the individual to the effects of the structural, social, political as well as moral levels of society.

In fact, Down Girl is largely an account of the gendered moral relationship and the numerous junctures between law, justice and morality. The focus on morality is evident when Manne contrasts sexism and misogyny. In Manne's account, sexism 
is "scientific (20)" and "wears a lab coat (80)". Misogyny is "moralistic (20)" and "goes on witch hunts (80)". While sexism rationalises, justifies and builds the ideological strand of the patriarchal social order, misogyny polices and enforces these governing norms. This explains the progress of some women, while other women face backlash. Obedience is rewarded; overstepping is punished. According to Manne, this definition also "builds in space" for intersectional insights (13). Though she goes a long way to recognise the benefits of intersectionality to moral thinking, she chiefly employs it as a disclaimer.

Misogyny understood as a moral relationship stands most clear when Manne proposes to evaluate misogyny from the perspective of its victims - to consider them as moral subjects (246). She argues against the humanist tendency to think of oppression in terms of dehumanisation and objectification of victims: Oppressive acts in order to make sense depends on the humanity of the oppressed (164). For one, it takes human comprehension to understand degradation. In this, Manne attempts to overturn the moral economy of misogyny which she characterizes as an exchange in which women (human givers) are assumed to owe men (human beings, that is, moral subjects), moral goods like emotional, social and political support, sex, care, unpaid housework as well as sympathy (106-113). She coins the neologism 'himpathy' to highlight the puzzling phenomenon that many people feel sorry for the compromised futures of convicted rapists such as golden boy Brock Turner and police officer Daniel Holtzclaw $(201,219)$. The moral economy of misogyny sympathises with the humiliation of men who are deprived of their entitled moral authority, and it exonerates men like Trump in cases of (sexual) violence and misconduct for instance in relation to their ex-wives. Women on the other hand cannot claim the things men are entitled to (authority, money, moral subjectivity, or presidencies) without being deemed nasty.

This is why Clinton lost (249-278), and the driving force behind Down Girl seems to be Manne's gloominess about it. She wants to scrutinize the unjust morality that prompted Americans to vote, not for a capable woman, but for an incompetent man whom Manne more than once describes as narcissistic $(128,266)$. In so doing, she defeats her own aim to go past psychological framing and thereby she depoliticises the political engagements of Trump and his voters. Misogyny probably did play a part in Clinton's defeat, but perhaps many people also wanted Trump's politics? Even if those politics were lewd. Another that keeps crossing my mind: Trump is not the only president to benefit from the moral economy of misogyny. What kind of moral exchange and sexual agency were at stake in the case of Monica Lewinsky and Bill Clinton? An analysis of Clinton's technical definition of intercourse that did not include the blowjobs he received from Lewinsky as well as of Hillary's support of her husband could have progressed Manne's claims beyond obvious antagonisms.

Manne's account has some nuance to it, when she almost arrives at reading \#Yesallwomen, Incels, and the rise of the Trump-administration as parts of the same dialectic (e.g. 36, 53, 101f). However, her analysis lacks historical inquiry into the shifting meanings and conditions that form patriarchy and misogyny. Thereby she culturally, historically, and conceptually universalises both occurrences, not to mention that she bypasses theoretical traditions such as Marxism, Marxist feminism, as well as Simone De Beauvoir (mentioned only once, 135) that already discuss asymmetrical giving. It is peculiar that Manne does not relate her account of misogynistic moral economy to the Hegelian ethics of De Beauvoir. In De Beauvoir's reading of the master-and-slave-dialectic, the historical condition of woman lies beyond it - as a non-dialectic being - the absolute other whose consciousness cannot transcend. She is not even slave, only a supportive bystander in the existential project of consciousness belonging to man.

From within the tradition of moral philosophy, Down Girl adds a perspective on the gendered moral relationship to read along with the vast literature on reproductive work (asymmetrical giving) and existentialist feminist philosophy. I enjoy Manne's open-ended attitude in her continuous 
invitations for the reader to fill in the gaps. She writes straightforwardly and appealing. In purpose of reaching readers beyond peers, this is particularly refreshing. As a new framework for thinking about misogyny, I find it wanting, but Manne raises awareness to interesting discussions, and she insists on employing philosophy to think about contemporary times. I applaud this. Even if I find her cases cherry-picked. 